\title{
Aspects of Applying Ergonomic Tests in the Evaluation of Ballistic Body Armours Using the Example of Ballistic Vests
}

\author{
Bogdan $A^{1 *}$, Marszałek A ${ }^{1}$, Majchrzycka $K^{2}$, Brochocka $A^{2}$, Luczak $A^{1}$ and Zwolinska $\mathbf{M}^{1}$ \\ ${ }^{1}$ Department of Ergonomics, Central Institute for Labour Protection-National Research Institute, Czerniakowska Warsaw, Poland \\ ${ }^{2}$ Department of Personal Protective Equipment, Central Institute for Labour Protection-National Research Institute, Wierzbowa Lodz, Poland
}

\begin{abstract}
The main objective of using ballistic protection (such as ballistic vests) is to protect the human body from mechanical damage. In Poland, the requirements for ballistic vests and ballistic inserts are set out in PN-V 87000:2011 Light ballistic armour. Bullet-proof and fragmentation vests Requirements and tests. This standard lays particular emphasis on the quality of workmanship of the vest etc, ergonomics aspects are treated marginally. At the same time, the use of any elements that cover the body affects the process of heat exchange between the human body and the environment, and can cause thermal strain while performing various tasks which can affect the accuracy of user's actions. Hence it is important to determine the level of their impact on the physiological and psychological reactions of the vest user. In this paper the results of comprehensive ergonomic tests of ballistic armour are analyzed and an example of this type of research methodology, covering important aspects of the functioning of the body under strain conditions of effort and a thermal environment is presented. In order to conduct a broad assessment of the ergonomic aspects for selected vests, the following measurements were performed: thermal insulation of uniforms and vests; based on the result, a temperature range was determined in which the vests should be used in order to avoid negative heat sensations for the user; the impact of vests on physiological indicators of users; work comfort in vests, in laboratory and field tests; influence of vests on human psychological parameters.
\end{abstract}

Keywords: Ballistic vests; Ergonomics; Thermal insulation; Physiological factors; Psychological factors

\section{Introduction}

The main objective of using ballistic protection (such as ballistic vests) is to protect the human body from mechanical damage. In Poland, the requirements for ballistic vests and ballistic inserts are set out in PN-V 87000:2011 Light ballistic armour. This standard lays particular emphasis on the quality of workmanship of the vest, materials and components used to make it, and includes requirements for appearance, resistance to environmental factors, reliability and first and foremost, ballistic resistance. Only one clause is devoted to the ergonomics of vests "Requirements for resistance to environmental factors", which states: Ergonomic properties should be preserved in dry conditions at temperatures from $-40^{\circ} \mathrm{C}$ to $+50^{\circ} \mathrm{C}$. Vest ergonomic properties mean: possibility to be quickly put on and fitted to the body without assistance, unobstructed execution of activities expected to be executed by the user, accessibility and ease of use of pockets and hooks. The standard also indicates that testing the ergonomics of vests should be carried out 'manually' at a temperature of $-40^{\circ} \mathrm{C},+20^{\circ} \mathrm{C}$ and $+50^{\circ} \mathrm{C}$. On this basis, it can be assumed that only the comfort of use is indicated in the standard as sufficient, and to a limited extent.

At the same time, the use of any elements that cover the body affects the process of heat exchange between the human body and the environment, and can cause thermal strain while performing various tasks. The physical process of heat exchange between the human body and the environment are shown by equation (1) [1].

$$
M-W=\left(C+R+E_{s k}\right)+\left(C_{r e s}+E_{r e s}\right)+\left(S_{s k}+S_{c r}\right)
$$

Where:

$M$ - Metabolic heat production, $\mathrm{W} / \mathrm{m}^{2}$,

$W$ - Heat converted into mechanical power, $\mathrm{W} / \mathrm{m}^{2}$,

$C+R-$ Heat transferred to the environment by convection and radiation (so-called sensible heat), $\mathrm{W} / \mathrm{m}^{2}$,
$E_{s k}$ - Heat transferred to the environment by evaporation of perspiration from the skin surface (so-called latent heat), $\mathrm{W} / \mathrm{m}^{2}$,

$C_{\text {res }}$ - Heat transferred to the environment by convection through breathing, $\mathrm{W} / \mathrm{m}^{2}$,

$E_{\text {res }}$ - Heat transferred to the environment by evaporation through breathing, $\mathrm{W} / \mathrm{m}^{2}$,

$S_{s k}$ - Heat accumulated in the skin, $\mathrm{W} / \mathrm{m}^{2}$,

$S_{c r}$ - Heat accumulated in the body, $\mathrm{W} / \mathrm{m}^{2}$.

During work, a person usually cannot influence the metabolism (physical activity) that is responsible for the amount of heat produced by the body, as well as parameters of the surrounding environment, regulating the amount of heat transferred to the environment. The only factor which affects the amount of heat transferred to the environment is the clothing and personal protection equipment worn by the user.

Ballistic vests influence the amount of heat transferred to the environment in the process of convection and radiation (dry heat losses), and because of their weight (some vests weigh up to $30 \mathrm{~kg}$ ) the amount of heat generated in the body. When the amount of heat remaining in the body far exceeds the amount of heat transferred to the environment, body heat accumulation occurs, which may cause

*Corresponding author: Bogdan A, Department of Ergonomics, Central Institute for Labour Protection-National Research Institute, Czerniakowska Warsaw, Poland; E-mail: anbog@ciop.pl

Received October 24, 2012; Accepted November 28, 2012; Published December 06, 2012

Citation: Bogdan A, Marszałek A, Majchrzycka K, Brochocka A, Luczak A, et al. (2012) Aspects of Applying Ergonomic Tests in the Evaluation of Ballistic Body Armours Using the Example of Ballistic Vests. J Textile Sci Eng 2:123. doi:10.4172/2165-8064.1000123

Copyright: ๑ 2012 Bogdan A, et al. This is an open-access article distributed under the terms of the Creative Commons Attribution License, which permits unrestricted use, distribution, and reproduction in any medium, provided the original author and source are credited. 
an increase in the internal temperature above the permissible limit of $37 \pm 1^{\circ} \mathrm{C}$ (EN ISO 9886). An increase in internal temperature may lead to hyperthermia [2], and also contribute to an impairment of psychomotor skills of the employee. A hot environment, in which the forces responsible for the safety and security of people often work, may adversely affect their psychomotor performance. Research conducted by Pilcher, Nadler and Busch showed that a hot environment $\left(\geq 26.67^{\circ} \mathrm{C}\right.$ WBGT) in the highest degree causes a reduced level of concentration, perceptiveness, ability to efficiently solve mathematical problems and deterioration of reflexes (although in the studies by Grether, the reaction time was reduced in hot environmental conditions). Confirmation of the negative impact of heat on cognitive processes of vigilance and attention were also obtained in an experiment carried out among drivers, in traffic conditions, in a moderately hot environment. Ramsey showed further that in the conditions of $35^{\circ} \mathrm{C}$ WBGT a number of dangerous behaviours increased significantly, and in the range between $33^{\circ} \mathrm{C}$ to $35^{\circ} \mathrm{C}$ WBGT, the greatest reduction in the quality of motor tasks was observed.

Other research, designed to assess the influence of personal protection of protective clothing consisting of overalls and helmets on the physiological processes and cognitive function of pilots, has shown the occurrence of heat stress at $40^{\circ} \mathrm{C}$ by physiological indicators (increase in skin temperature, internal temperature and frequency of heart contractions) and an impaired vigilance (increased number of errors) [3]. A reduced level of vigilance was also observed in research conducted among members of civil emergency services, using clothing for protection against biological and chemical threats. It turned out that after one hour and a half in a simulation exercise in the heat, vigilance in detecting a signal decreased by about $55 \%$, and after two hours of exposure to heat $\left(35^{\circ} \mathrm{C}, 60 \%\right.$ relative humidity) a decrease in the efficiency of firing weapons ranged between 19 and 22\% [4].

On this basis, it can be assumed that the presence of a thermal strain of ballistic vest users can affect the accuracy of their actions. Hence it is important to determine the level of their impact on the physiological and psychological reactions of the vest user.

In this paper the results of comprehensive ergonomic tests of ballistic armour are analyzed and an example of this type of research methodology, covering important aspects of the functioning of the body under strain conditions of effort and a thermal environment is presented.

\section{Research Material}

Bullet-proof and fragmentation vests were designed as part of the implementation of the key project number WNDPOIG.01.03.01-10-005/08, 'Modern ballistic body amours and covers for transportation means as well as for buildings, made on a basis of textile composites' (Leader: Institute of Security Technologies MORATEX). Three prototypes of vests were tested tailored to specific work requirements of three groups of users. Each vest consisted of a textile layer typical of each studied groups and one type of ballistic, composite inserts. The weight of the vests with inserts and equipment was $31.1 \mathrm{~kg}, 19.9 \mathrm{~kg}$ and $23.1 \mathrm{~kg}$, respectively for the each studied groups, coded: 1,2 or 3 .

In order to conduct a broad assessment of the ergonomic aspects for selected vests, the following measurements were performed:

- Thermal insulation of uniforms and vests; based on the result, a temperature range was determined in which the vests should be used in order to avoid negative heat sensations for the user
- The impact of vests on physiological indicators of users

- Work comfort in vests, in laboratory and field tests

- Influence of vests on human psychological parameters.

Test methods are presented in the next sections. Tests subjects were users of ballistic vests representing the three groups of users. In each scope of the research, participants belonged to different demographic groups.

\section{Thermal Insulation of Ballistic Body Armours}

At the first stage of the ergonomic tests, thermal insulation of uniforms used by various groups of users was determined, and then of the ballistic vests themselves in accordance with the methodology of research presented in the standard EN ISO 15831:2006. For the tests, summer uniforms were used, comprising of cotton underwear (boxers, T-shirt and thin socks) and the uniform used by each studied groups of users $(1,2$ or 3$)$ as well as winter uniforms consisting additionally of a long-sleeved thermal shirt, thermal trousers, a woolen hat, thick socks, insulated gloves, boots and insulated coveralls. Effective thermal insulation of clothing used in the summer (calculated with the use of the serial method) was from 1.02 clo (group 2) to 1.19 clo (group 3), in the winter-from 1.26 clo (group 1) to 2.43 clo (group 2). In the next step, thermal insulation of ballistic vests themselves was examined. The highest effective thermal insulation (calculated using the serial method) was determined for vest of group 1 ( $0.56 \mathrm{clo})$, and the lowest for the vest of group 2 ( $0.28 \mathrm{clo})$. Such a high thermal insulation of the entire set worn by users can disrupt the transfer of heat from the human body. On the basis of the analysis of the working environment in which the heat exchange between an user's body and the environment will be leveled off, it was found that users dressed in the summer uniform and a ballistic vest, when executing hard work (at a metabolic rate of $230 \mathrm{~W} / \mathrm{m}^{2}$ ) should be in an ambient temperature ranging between $-5^{\circ} \mathrm{C}$ and $10^{\circ} \mathrm{C}$, while users dressed in the winter uniform and a ballistic vest should be in an ambient temperature between $-20^{\circ} \mathrm{C}$ and $5^{\circ} \mathrm{C}$. In reality, work while wearing this type of armour is performed regardless of environmental parameters. In particular, there is large divergence for the summer uniform because the work environment is then characterized by temperatures higher than $+15^{\circ} \mathrm{C}$.

On this basis, it can be concluded that both the uniform and the ballistic vest should also be evaluated in terms of thermal insulation. This type of research also shows a need for using active and passive methods to transfer heat from the human body, such as through the use of PCM in the underwear under the uniform [5].

\section{Influence of Ballistic Armour on Physiological Responses}

The purpose of physiological research was to determine the extent of changes of selected physiological indicators during exercise of varying intensity, in terms of hot and cold thermal environment during use of ballistic armour prototypes (vest, helmet, ballistic shield) and in conditions without the use of ballistic vests. The research was conducted in two types of environmental conditions (PN-V 87000:2011): summer (air temperature equal to $+35^{\circ} \mathrm{C}, 40 \%$ relative humidity, air velocity 0.4 $\mathrm{m} / \mathrm{s}$ ) and winter (respectively $20^{\circ} \mathrm{C}$ and $0.4 \mathrm{~m} / \mathrm{s}$ ). For the sets of clothes (underwear, uniform and ballistic vest) used in the tests, thermal insulation was determined using the method described above. The tests examined changes in internal temperature, heart rate, temperature and relative humidity beneath the underwear and changes in body weight and clothes before and after the test. Additionally, subjective user evaluations were collected relating to the feeling of the heat in whole 
Citation: Bogdan A, Marszałek A, Majchrzycka K, Brochocka A, Luczak A, et al. (2012) Aspects of Applying Ergonomic Tests in the Evaluation of Ballistic Body Armours Using the Example of Ballistic Vests. J Textile Sci Eng 2:123. doi:10.4172/2165-8064.1000123

Page 3 of 5

body (EN-ISO 10551:2002), experienced fatigue [6] and sensing skin moisture [7]. During the tests, volunteers performed various activities, as they are performed by them in real conditions (BS 7971-2:2002), such as arm movements in a standing position (with a ballistic shield), sitting down and getting up off the floor, lying down and standing up, crawling, simulated boarding on and getting off a van, getting ready to shoot while in a standing, kneeling and lying position, running with a weight on the back and a weight pulled on the ground [8] (Figure 1).

Analysis of results showed no statistically significant differences between the variants of the test with and without a ballistic vest, which was mainly the effect of too small a population of test subjects (four people). It was found that exercise was generally easier to perform in a cold environment rather than in a hot one. In such conditions, internal temperature changes and the weighted average skin temperature tested were smaller with a ballistic vest than without it. The temperature and humidity beneath the underwear was out of the range of comfort indicating that the layers of clothing provided too much thermal insulation. In a hot environment, the duration of the exercise was significantly reduced when the vest with the highest weight (group 1) was used, where the tests were about half the time shorter than in the other test groups. Higher changes in internal temperature were limited by the duration of the test [9]. Both changes in the weighted average skin temperature and the temperature and relative humidity beneath the underwear occurred similarly in the test when a ballistic vest was
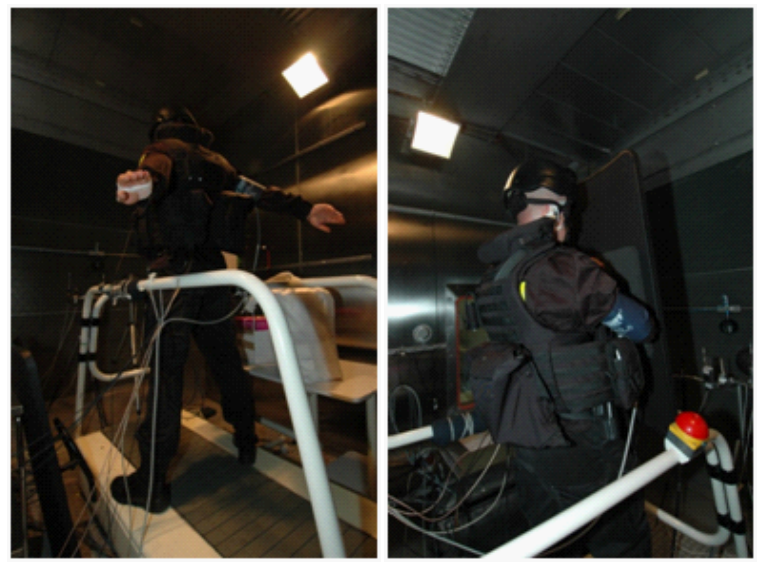

Figure 1: Testing ballistic armour in a climate chamber: arm movements (left) and marching with a ballistic shield.

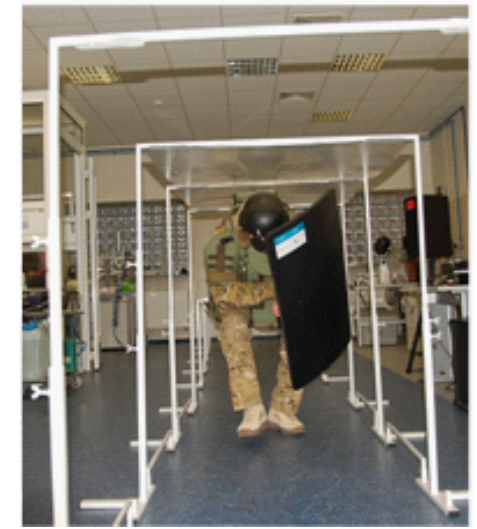

Figure 2: Walking in a crouched position.

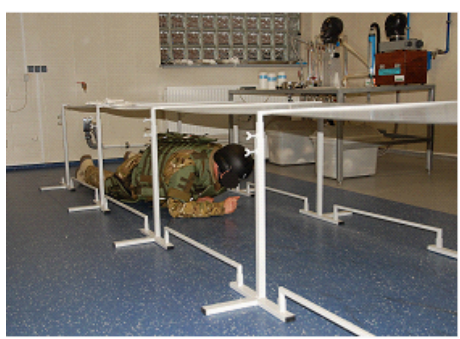

Figure 3: Test crawling in a tunnel.

worn and when it was not. Additionally, thermal sensations of the body in hot environment tests have shown that the majority of the test subjects defined the level of the feeling of heat as maximum, already without a ballistic vest, so wearing a vest in such conditions was equally uncomfortable [10].

It can be concluded that while working in ballistic vests, significant thermal strain of the body occurred, especially in hot environments, because of a great limitation of heat transfer to the environment. Conducting such tests may give clues to determine the safe duration of use of protective measures and identify the main obstacles to their use (designs of vest covers and properties of ballistic inserts), which contributes to their elimination. Physiological studies can also compare different armour designs, which is helpful in selecting the best solution to be implemented in practice.

\section{Work Comfort in Ballistic Armour}

The research in the comfort of work while wearing ballistic vests was carried in laboratory and field conditions. In both environments, tests were carried out in two stages: in the first stage volunteers were wearing clothes and uniforms suitable for the season; in the second stage they were also wearing a ballistic vest. In laboratory tests the volunteers performed the following activities [11]: putting armour on, fitting and making the necessary adjustment, walking in an upright position-100 $\mathrm{m}$ at $6 \mathrm{~km} / \mathrm{h}$ for 10 minutes, walking in a crouching position $1.3 \mathrm{~m}-140$ $\mathrm{m}$ for 5 minutes, crawling in a tunnel about $70 \mathrm{~cm}$ high for 5 minutes-a total distance of $70 \mathrm{~m}$, mounting and dismounting a ladder to a total height of $20 \mathrm{~m}$, filling baskets with strips of rubber 20 times for 10 minutes, moving successively to a distance of $10 \mathrm{~m}$ and laying bags of sand in a pile of 20, each bag weighing $12 \mathrm{~kg}$; simulated entry and exit to/from a vehicle at least 5 repetitions, getting ready to shoot in a standing position, kneeling and lying down at least 5 repetitions etc. Examples are shown in figures 2 and 3.

Laboratory tests were performed in normal conditions, i.e. at $20 \pm$ $2^{\circ} \mathrm{C}$ and relative humidity of $65 \pm 5 \%$. Field tests were conducted in hot conditions (lack of rainfall, temperature close to $26^{\circ} \mathrm{C}$ ). During the test, volunteers performed such activities as crossing a balance beam etc. (Figures 4-6). The duration of each test was about 30 minutes.

After completion of the test, each participant answered a questionnaire including questions on such issues as the functionality of ballistic products, thermal sensations of the body, feeling of skin or clothing dampness [11].

On this basis, operations during which users experienced difficulties due to the use of a ballistic vest (such as when getting out of a car or crawling), thermal discomfort, shoulder and neck pain occurring after the end of the test and musculoskeletal system discomfort. The main discomfort caused by the ballistic vests pertained to thermal sensations. Most test subjects indicated that they evaluate thermal environment 
Citation: Bogdan A, Marszałek A, Majchrzycka K, Brochocka A, Luczak A, et al. (2012) Aspects of Applying Ergonomic Tests in the Evaluation of Ballistic Body Armours Using the Example of Ballistic Vests. J Textile Sci Eng 2:123. doi:10.4172/2165-8064.1000123

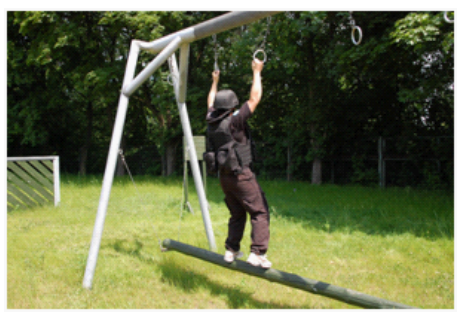

Figure 4: Crossing a balance beam

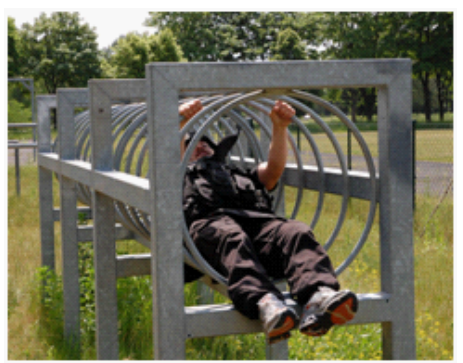

Figure 5: Going through a series of rigidly mounted upright rims.

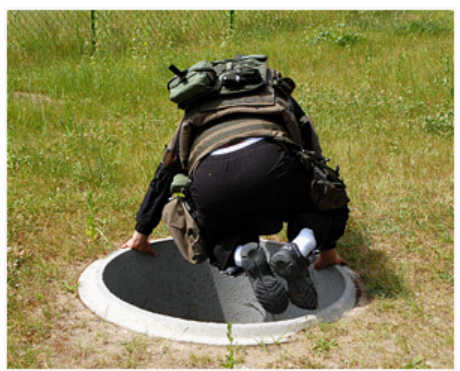

Figure 6: Jump into a manhole.

as +2 (very warm) and +3 (hot) according to the ASHRAE thermal sensation scale. These impressions were consistent with the feelings of skin dampness (which was evaluated as damp and very damp by most users) and clothing (evaluated as damp and wet). For all users this aspect caused considerable discomfort. In fields tests it was determined that all users reported discomfort in the musculoskeletal system (pain in the lumbar spine), thermal discomfort and limitations in the movement of the head, neck and shoulders.

A study of the results of tests confirmed the validity of obtaining ergonomic evaluation in laboratory and field conditions. Comparing the results of the questionnaires completed in laboratory and field conditions, it has been demonstrated that a higher percentage of negative responses were provided in field conditions, so this kind of test gives a picture that more closely resembles the actual conditions in which ballistic armour is used. In fields test, subjects traversed greater distances and the thermal environment was also less favourable. In field conditions activities were performed with more dynamic movements to keep balance and due to the higher variation of tasks.

\section{Influence of Body Armour on Psychological Parameters}

During operational laboratory and field testing, an analysis of changes in psychological well-being, psychomotor skills and cognitive processes was also carried out. The Greanjean scale was used in the tests (to assess the psychological strain), a complex reaction time test (to evaluate reflexes) and a TUS test (to evaluate attention and perception).

Test results allow us to conclude that the use of ballistic armour, such as ballistic vests and fragmentation vests was associated with worsening of subjective feelings of mood and experienced fatigue, both in the laboratory experiment and in field conditions on the test range. However, deterioration of psychological well-being was not accompanied by worsening of objective indicators of performance of the subjects, and in the laboratory experiment improved reflexes and speed of mental work was observed after the test compared to the results before they started. Experiments taking place without the use of ballistic armour was accompanied by improvement in psychological well-being and faster pace of mental work after completion of tests in relation to the results before they started.

Therefore, it seems reasonable to extend the exposure time of a person wearing protective clothing to factors present in his environment (e.g. physical effort of a certain value) for tests aimed to assess the ergonomics of this protective clothing.

\section{Summary}

The study indicated a need for a comprehensive assessment of ballistic products with respect to their ergonomics. Ballistic armour should be subject to the same tests that are used for other types of individual protective gear, such as thermal insulation and comfort of use. Such tests will make it possible to diagnose and optimize the design and materials used to obtain the best fit and protection, and decrease the discomfort caused by their use.

Due to a need for using ballistic armour in different environmental thermal conditions and performance of efforts of various levels of intensity, including various body positions, and thereby often use ballistic armour of a considerable weight, a detailed assessment of this protection should also be based on the results of physiological and psychological tests among users who are exposed to environmental heat conditions close to the actual heat conditions and will engage in activities similar to those carried out on duty. This will make it possible to avoid excessive thermal strain by modifications at the design stage of ballistic armour products.

\section{Acknowledgment}

The research was carried out within the framework of Innovative EconomyNational Cohesion Strategy as a Key Project No. WND-POIG 01.03.01-10-005/08 entitled: "Modern ballistic body armours and covers for transportation means as well as for buildings made on the basis of textile composites" supported by the European Regional Development Fund.

\section{References}

1. Wieslawa B, Magdalena K, Kazimierz K, Anna B (2010) Thermal Manikin Evaluation of PCM Cooling Vests. Fibres Text East Eur 18: 70-74

2. Thake CD, Price MJ (2007) Reducing uncompensable heat stress in a bomb disposal (EOD) suit: A laboratory based assessment. 12th International Conference on Environmental Ergonomics, Slovenia.

3. Faerevik H, Reinertsen RE (2003) Effects of wearing aircrew protective clothing on physiological and cognitive responses under various ambient conditions. Ergonomics 46: 780-799.

4. Krueger GP (2001) Psychological and performance effects of chemicalbiological protective clothing and equipment. Mil Med 166: 41-43.

5. PN EN ISO 9886:2005 (2005) Ergonomics-Evaluation of thermal strain by physiological measurements. 
Citation: Bogdan A, Marszałek A, Majchrzycka K, Brochocka A, Luczak A, et al. (2012) Aspects of Applying Ergonomic Tests in the Evaluation of Ballistic Body Armours Using the Example of Ballistic Vests. J Textile Sci Eng 2:123. doi:10.4172/2165-8064.1000123

Page 5 of 5

6. Borg GA (1982) Psychophysical bases of perceived exertion. Med Sci Sports Exerc 14: 377-381.

7. Nielsen R, Endrusick TL (1990) Sensations of temperature and humidity during alternative work/rest and the influence of underwear knit structure. Ergonomics 33: $221-234$

8. UNE EN ISO 10551:2002 (2002) Ergonomics of the Thermal EnvironmentAssessment of The Influence of The Thermal Environment Using Subjective Judgment Scales.
9. BS 7971-2:2002: Protective clothing and equipment for use in violent situations and in training. Part 1: General requirements.

10. ISO 15831:2004 (2004) Clothing-Physiological effects-Measurement of thermal insulation by means of a thermal manikin.

11. Majchrzycka K, Brochocka A, Deckchairs K, Luczak V (2011) Methodology for assessing the performance of ballistic. Textile Review 9. 